\title{
COVID-19, ENTRE LO COTIDIANO Y EL ACONTECIMIENTO: UNA INTERPRETACIÓN DESDE LA FILOSOFÍA DE ZIZEK
}

Manuel Flores Sánchez

José María Morán Carrillo

Universidad Pablo de Olavide

\section{RESUMEN}

El texto parte de la descomposición en factores de la expresión "vida cotidiana" a través de los distintos análisis que se han realizado. El resultado es que tras el término "vida cotidiana" late una tensión dialéctica entre "lo cotidiano" y "el acontecimiento". La epidemia covid-19 se puede clasificar como un acontecimiento y ha supuesto la irrupción de "Lo Real" en las coordenadas simbólicas de nuestra sociedad occidental y europea. Esta irrupción ha provocado un trauma que hace esperar la consecuencia de la reinvención del pasado y la reinterpretación de la vida cotidiana.

Palabras clave: Vida cotidiana; Acontecimiento; Covid-19; Trauma.

\begin{abstract}
The text is rooted in the decomposition of the expression "everyday life" into factors through the different analyses carried out. The result is that behind the term "everyday life" there is a dialectic tension between "the everyday" and "the event". The Covid-19 epidemic can be classified as an event and has meant the irruption of "The Real" into the
\end{abstract}


symbolic coordinates of our Western and European society. This eruption has caused a trauma that forces us to wait for the consequence of the reinvention of the past and the reinterpretation of everyday life.

Keywords: Everyday life; Event; Covid-19; Trauma.

\section{LO COTIDIANO Y EL ACONTECIMIENTO}

Christian Lalive D'Epinay (2008) elabora una precisión conceptual sobre la vida cotidiana que consideramos altamente interesante como punto de partida para nuestra propuesta de debate sobre las particularidades del impacto de la epidemia covid-19 en nuestras sociedades occidentales europeas.

Para dicho autor, la expresión "vida cotidiana" engloba y supera los términos "cotidiano", "cotidianeidad", "rutina" o "banalidad" y determina el campo de la vida cotidiana como aquel en el que se desarrolla una tensión dialéctica entre "lo cotidiano" y "el acontecimiento" - lo extra-ordinario-. Esta tensión se desarrollaría de muchas maneras: como un proceso de "domesticación" - término propio- del acontecimiento inesperado (deseado/no deseado, agradable/desagradable), como una expectativa o búsqueda del acontecimiento o incluso como la base de producción del acontecimiento. Una sirena de policía, un incendio, "el cupón de la ONCE" (y la esperanza de obtener su premio) o la cabalgata de Reyes Magos en Higuera de la Sierra (y su preparación) materializan ejemplos de acontecimientos que, en confluencias de varia naturaleza con lo rutinario, componen la vida cotidiana.

Muchos autores han realizado interesantes trabajos sobre esta cuestión, teniendo en cuenta explícita o implícitamente la tensión dialéctica entre lo cotidiano y el acontecimiento, aun cuando la terminología puede variar entre ellos. Así, Berger y Luckman (1969), Elias (1978/1995), Goffman (1981) o De Certeau (1996).

En sus versiones liminales, nos encontraríamos a Duvignaud (1990) y Badiou (1999). Duvignaud se centra en el acontecimiento como anomia, arrancando de los estudios de Durkheim sobre la normatividad social. En efecto, la anomia no es una forma de desobediencia de las normas sociales sino el nacimiento de un escenario nuevo. Pero no es el escenario nuevo y tampoco el antiguo, es el trance que conduce de uno a otro. Se identifica más con un proceso, nunca con una evolución. A veces será un momento, jamás un estado. Siempre será incompatible con el curso anterior de las cosas. De cualquier manera, siguiendo a Duvignaud, será un choque brutal que abre una brecha, una "fisura, catástrofe presentida, vivida, soñada" en la cultura que es descubierta en lo 
“infra-ordinario" en la vida cotidiana regulada por las normas establecidas (Duvignaud, 1990: 45).

Por su parte, Badiou dota al acontecimiento de dos características. La primera consiste en la imposibilidad de previsión de este desde lo que se conoce, se sabe, se prevé en el momento que ocurre el evento. La segunda tiene que ver con la novedad que el acontecimiento introduce, la creación de unas nuevas condiciones de posibilidad. No es solo un evento significativo o notable, sino una verdad emergente. Sin embargo, Badiou limita el acontecimiento a cuatro campos: amor, ciencia, política y arte.

La noción de acontecimiento que constituye la base filosófica sobre la que se asienta mayoritariamente hoy en día este concepto, incluyendo al autor que tomaremos de referencia para este artículo de debate -Zizek_-, es de Martin Heidegger. Como aclara Esperón (2018: 22-23),

"el acontecimiento no pude ser clasificado ni se deja conceptualizar de acuerdo a los parámetros aristotélicos de género, especie y diferencia específica, o a los parámetros tradicionales historiográficos que suponen que todo hecho es causado por algo y produce efectos; pues el acontecimiento nombra algo previo, no en el orden temporal cronológico sino en el orden ontológico, que escapa y se rehúsa a las estructuras de clasificaciones racionales. En este sentido, el acontecimiento irrumpe intempestivamente y pone en suspenso a la sucesión normal de los hechos. El acontecimiento nombra la original e inesperada aparición de la novedad, que en su condición esencial desestabiliza y resignifica tanto el presente como el pasado y abre inconmensurables posibilidades proyectadas hacia el futuro; por consiguiente, el acontecimiento mienta la instauración de un nuevo horizonte de sentido, es decir, conlleva una dimensión originaria en la comprensión ontológica del ser, el tiempo, las cosas y el lugar del ser-humano en este nuevo contexto".

\section{LA EPIDEMIA Y EL ACONTECIMIENTO}

A pesar de que, como descubrió Bauman (2012), vivimos en una sociedad líquida en la que las pautas tienden a derretirse y las predeterminaciones se desdibujan dando lugar a un individuo que tiene que inventar sus propios asideros - aunque no en el sentido existencialista, sino en tanto que "privatizador" - , es innegable que la vida cotidiana ha seguido existiendo. Tiempos festivos, ritos de compras, espacios y formas de sociabilidad, jornada laboral, etc. han resistido la licuefacción de los tiempos y han permanecido como "sólidos" socialmente compartidos.

Dicho esto, la covid-19, en su hiperbólica denominación "pandemia”, ha provocado, provoca y provocará durante un plazo indeterminado - incertidumbre - cambios en lo cotidiano (espacio interpersonal, formas de saludar y de mostrar afecto, censura de conductas, imagen pública, etc.), pero también en los acontecimientos (comparecencias 
televisivas de las autoridades, infracciones, estadísticas de mortalidad, modificación de la situación laboral, etc.).

Es indudable que la vida diaria ha sufrido una significativa transformación cualesquiera sea la dimensión observada. El presente número monográfico de esta revista representa un esfuerzo intelectual por profundizar en dicha transformación, por lo que no consideramos necesario ahondar en ello. Sin embargo, la hipótesis que presentamos quisiera enunciar la posibilidad de que exista un "punto cero", un momento previo a los procesos descritos por la doctrina o lo intuido por el sentido común, que condiciona por completo la vida cotidiana peripandémica y postpandémica.

\section{LA EPIDEMIA COMO IMPOSIBILIDAD}

Una de las más famosas citas de Hegel reza: "Lo único que nos enseña la historia es que ella no nos ha enseñado nada”. A este respecto, escribe Zizek (2020: 8):

"Lo único que está claro es que el virus romperá los cimientos de nuestras vidas, causando no solo una inmensa cantidad de sufrimiento sino también estragos económicos posiblemente peores que la Gran Recesión. No hay vuelta a la normalidad, la nueva "normalidad" tendrá que ser construida sobre las ruinas de nuestras viejas vidas, o nos encontraremos en una nueva barbarie cuyos signos ya son claramente discernibles. No bastará con tratar la epidemia como un desafortunado accidente, para librarse de sus consecuencias y volver al buen funcionamiento de la antigua forma de hacer las cosas, con tal vez, algunos ajustes en nuestras medidas de salud".

Lo que realiza Zizek en su ensayo sobre la pandemia es una lectura lacaniana de Hegel, al tiempo que impugna de forma indirecta el constructo sociológico de la vida cotidiana o, al menos, su validez (in)mediata.

Para abordar el enunciado de Zizek, necesitamos conocer cómo Lacan (1994) diferencia entre Lo Simbólico y Lo Real. Lo Simbólico designa, para este autor, el conjunto/totalidad de las relaciones humanas y la posición de los sujetos (género, clase, etc.) en el orden social. Lo Simbólico está contenido en el lenguaje y su normatividad, y en los textos del autor francés se puede encontrar intercambiado con la expresión "gran Otro", en tanto que orden y representación de lo prexistente al individuo, las imposiciones que de la misma forma que lo sojuzgan, lo constituyen como sujeto dentro de la cultura.

Por su parte, Lo Real circunda aquello que se resiste a su simbolización o representación a través del lenguaje. Lo Real se sitúa más allá de lo significante (que podríamos identificar con el acontecimiento) y lo insignificante (propio de lo cotidiano), pues tanto en uno como en otro caso, el fenómeno puede ser representado. 
La pandemia covid-19 era una imposibilidad o, por mejor decir, no-era una posibilidad dentro de Lo Simbólico de nuestra cultura (ajena a la literatura académica); todo lo más, sus homólogos se asociaban a los radicalmente-otros:

- A los otros-otros. El término pandemia se asociaba, hasta no hace mucho tiempo, a noticias marginales situadas en países no occidentales, por ejemplo, el Zika en África. La declaración por parte de la OMS de pandemia suponía contagios transnacionales en continentes del no-Primer Mundo, con alguna repercusión-espectáculo en el Estado Español, como el Ébola en 2014, que solo afectó a una persona del ámbito sanitario y tuvo una gran repercusión en los medios de comunicación. Importa recordar que el Ébola tiene una letalidad de casi el 50\%, mucho más alta que la covid-19.

- A los nosotros-otros. Tampoco las pandemias europeas histórica, tales como la peste y la gripe en sus diferentes variantes letales, se nos presentan como cotidianas puesto que pertenecen a un "mundo primitivo" ajeno al paradigma tecnológico omnipotente actual.

- A nuestros-otros. El VIH estaba socialmente asociadas a la homosexualidad y la drogadicción en el momento de su explosión, que no son sino unos "otros" entre nosotros. La percepción del SIDA se ha transformado con la extensión del mismo a personas heterosexuales y la posibilidad de convertirla en una enfermedad crónica a través de la medicación.

- Los otros-ficción. Las películas de Hollywood sobre pandemias o zombis han adelantado muchos de los escenarios que estamos viviendo, pero siempre han ocurrido en un Estados Unidos distópico, en el Imperio (Negri y Hardt, 2002), en todos los lugares y en ninguno en concreto.

Es este el sentido en el que interpretamos el adagio hegeliano Lo único que nos enseña la historia es que ella no nos ha enseñado nada. Aunque, inspirándonos en Bauman (2012), la debilidad referencial parece ser una característica de la modernidad avanzada que habitamos.

Pero continuemos con la separación entre lo Real y lo Simbólico. Para Lacan (1988), el significante cava un surco en Lo Real, en la falta, en la ausencia. Por un lado, esta falta de completud de Lo Simbólico habilita la libertad del sujeto, pues si Lo Simbólico fuera un orden completo, omniabarcante, descriptor y prescriptor de cada hecho, relación y evento, el sujeto estaría predefinido en cada una de sus dimensiones y no cabrían nuevas simbolizaciones, ni, por ende, elección. En segundo lugar, y más importante para la hipótesis que estamos construyendo, la relación entre Lo Real y Lo Simbólico es siempre traumática. Zizek suele emplear el ejemplo de los atentados del 11S en Nueva York para ilustrar cómo irrumpe Lo Real en Lo Simbólico y describir sus efectos. 
A lo largo de la historia y a lo ancho del mundo, ha existido esta emergencia brusca de Lo Real por sobre Lo Simbólico, este vacío, esta falla dentro del sistema. Nosotros pensamos que la epidemia covid-19 supone una de ellas dada la falta de simbolización de la misma y la imposibilidad de preverla.

\section{EL PUNTO CERO DE LA VIDA COTIDIANA}

Es en este punto en el que situamos el punto cero de la vida cotidiana. Antes de que la sociedad construya nuevas relaciones, antes de que se dé la tensión dialéctica entre lo cotidiano y el acontecimiento, antes, si quiera, de que se produzca el estado de anomia, hay/no hay algo/nada. Este es el sentido en el que Zizek (2020: 8) elegía la expresión "la nueva 'normalidad' tendrá que ser construida sobre las ruinas de nuestras viejas vidas".

Creemos encontrar evidencias de este punto cero en diferentes hechos observados con respecto a la vivencia ciudadana de la situación epidémica y su paralelo en los textos de Zizek. Sin ánimo de exhaustividad podemos mencionar algunos ejemplos:

- Existe una generalizada sensación de "pesadilla", de irrealidad completa, de absurdo.

- Las nuevas rutinas se han convertido en desadaptativas.

- Hay un abierto pánico al futuro, a la incertidumbre, al tiempo que una búsqueda casi obsesiva del placer "por si acaso nos confinan otra vez".

Esta experiencia compartida coincide con la fantasía espectral "que no se ve en ninguna parte y que por eso es tan poderosa" (Zizek, 2020: 67). Cuando "ese agente espectral pasa a formar parte de nuestra realidad [...], su poder se localiza, se convierte en algo con lo que podemos lidiar (aunque perdamos la batalla)". Mientras tanto, "nos quedamos atrapados en una paranoia ansiosa" (Ibidem: 68).

No resulta difícil emparejar este estado social provocado por la epidemia covid-19 con la definición de trauma, "choque o impresión emocional muy intensos causados por algún hecho o acontecimiento negativo que produce en el subconsciente de una persona una huella duradera que no puede o tarda en superar" (Real Academia Española de la Lengua, 2001).

Siguiendo a Zizek (2008: 9), la situación sociopolítica es tan capaz de provocar intrusiones externas, traumas, interrupciones brutales sin sentido que destruyen la textura simbólica de la identidad del sujeto, como lo son un desastre natural, una enfermedad degenerativa o una guerra. Como ya hemos apuntado, de la mayoría de emergencias de Lo Real podemos encontrar ejemplos históricos, aunque parece que lo novedoso de la situación actual es la acentuación de la falta de sentido que padecemos en nuestra era "desencantada" en un sentido weberiano, post-religiosa. 
Todos los casos de experiencia traumática, con independencia de su génesis social, natural, biológica, simbólica o cualquier otra, conducen al mismo resultado: el sujeto que sobrevive a su propia muerte padece una suerte de borrado de su identidad simbólica. Hay una discontinuidad entre el sujeto "postraumático" y el antiguo sujeto (Ibidem: 12). Hay, tras el choque, un nuevo sujeto con una conocida configuración consistente en falta de compromiso emocional, indiferencia y desapego (Ibidem: 13).

El nuevo sujeto no es una mera transformación del antiguo. Es cierto que en aquel sobreviven rastros de este, pero están reestructurados, desgarrados de su cosmos significativo y puestos en un contexto totalmente nuevo (Ibidem: 23).

En lo que interesa a este trabajo, el nuevo sujeto modificará la visión y el contenido de su propio pasado, especialmente de su vida cotidiana. El trauma creará otra-historia en un pasado que no habrá existido (Ibidem: 24). Esto es tanto como decir que la vida cotidiana que está en construcción o que habrá de ser tejida, se alzará ya no sobre las cenizas, sino desde la ficción de lo que fue, que realiza un sujeto reducido a mera subjetividad, con el peligro que ello conlleva de control ideológico, en el sentido marxiano, de lo simbólico, aunque este punto excede el objeto de este breve trabajo.

\section{CONCLUSIONES}

La vida cotidiana está atravesada por una tensión permanente entre la novedad y la rutina. El acontecimiento es la novedad que desestabiliza la comprensión habitual de los hechos y el funcionamiento del mundo y crea un nuevo horizonte de sentido.

El conjunto de hechos y circunstancias que son y rodean a la covid-19 ha supuesto un verdadero acontecimiento en nuestras sociedades que las transformarán, pero nosotros hemos querido señalar al momento exacto en el que aún no hay transformación trauma- y que condiciona el proceso de reconstrucción subjetiva y social en tanto que supone un verdadero desgarro de sentido y expone a la vulnerabilidad. 


\section{REFERENCIAS BIBLIOGRÁFICAS}

Badiou, Alain (1999). El ser y el acontecimiento. Buenos Aires: Manantial.

Bauman, Zygmunt (2012) La modernidad líquida. Buenos Aires: Fondo de Cultura Económica.

Berger, Peter. L. y Thomas Luckmann (1969) La construcción social de la realidad. Buenos Aires: Amorrortu.

De Certeau, Michel (1996) La invención de lo cotidiano: artes de hacer. I, Volumen 1. México D.F.: Universidad Iberoamericana.

Elias, Norbert (1978/1995) "Sur le concept de vie quotidienne". Cahiers internationaux de sociologie, 99: 237-246.

Esperón, Juan Pablo (2008) "Pensar la irrupción de la novedad sobre el abismo. Heidegger y el acontecimiento”. Franciscanum, 60(169): 19-37.

Goffman, Erving (1981) La presentación de la persona en la vida cotidiana. Buenos Aires: Amorrortu.

Lacan, Jacques (1994) Seminario IV: La relación de objeto. Buenos Aires: Paidós. (1988) El seminario de Jacques Lacan, libro 7: la etica del psicoanalisis 1959-1960. Buenos Aires: Paidós.

Lalive D’Epinay, Christian (2008) "La vida cotidiana: construcción de un concepto sociológico y antropológico". Sociedad Hoy, 14: 9-31.

Negri, Antonio, y Michael Hardt (2002) Imperio. Barcelona: Paidós Ibérica.

Real Academia Española de la Lengua (2001) Diccionario de la lengua española. 22a ed. Madrid: Autor.

Weber, Max (1921/1997) Economía y sociedad: esbozo de sociología comprensiva. México D.F.: Fondo de Cultura Económica.

Zizek, Slavoj (2020) Pandemic!: COVID-19 Shakes the World. New York and London: OR Books.

(2008) "Descartes and the post-traumatic subject". Filozofski vestnik, XXIX(2): 9-29. 